\title{
Past changes in species diversity: A view from the mountains
}

\author{
Davnah Payne1, C. Hoorn², C. Randin ${ }^{3}$ and S.G.A. Flantua ${ }^{4}$
}

\author{
Mountains host a spectacular diversity of species. Yet current species distribution is only a snapshot in time that bears \\ the memory of past geomorphological and climatic changes. Understanding past changes is key to interpret current \\ patterns and inform mountain biodiversity conservation and management in the future.
}

\begin{abstract}
The present: mountains are (bio)diverse Terrestrial mountains sensu Körner et al. (2011; 2017) cover approximately one-tenth of the total land surface. These mountains vary in many ways, from their geological history to their appearance and ecosystems. The Chaîne des Puys in France or Mount Fujiyama in Japan are volcanic, whereas the Rocky Mountains of North America are socalled fold mountains that resulted from the thickening of the Earth's crust. In the Black Hills of South Dakota, USA, mountains are dome-shaped, whereas the table-top mountains of Venezuela are plateaus.
\end{abstract}

Within the same African continent, some mountains like Mount Kilimanjaro are high and capped with ice, while others such as the Eastern Arc Mountains are lower and mostly covered with dense tropical forest. Some, like the Kohala Mountains of Hawaii, USA, cover a small geographic area, while others like the Himalayas are immense and stretch across several countries and thousands of kilometers. And yet as diverse as they are (Gordon 2018), all these mountains share a common characteristic: they host a spectacular diversity of species, of which many are endemic, and contribute disproportionately to the terrestrial biodiversity on Earth (Rahbek et al. 2019a). The Cape Fold belt of South Africa alone has $68 \%$ endemism across the 9000 plant species known to science (IPBES 2018), the Andes are home to an approximate 45,000 plant species (Myers et al. 2000), and more than half of the world's "biodiversity hotspots" are entirely or partly in mountainous areas (Körner and Ohsawa 2005).

\section{The past: geomorphology, cli- mate, and evolution}

The current distribution of mountain species and their high levels of richness and endemicity just represent a snapshot in time that bears the collective memory of the millions of years of geomorphological and climatic changes that drove species along individual evolutionary trajectories. These environmental drivers often left almost intangible traces, making the reconstruction of the historical biogeography of mountains and their biodiversity an intriguing puzzle. Yet, the general consensus is that uplift events (Hoorn et al. 2018) set the stage for species' evolution by providing novel ecological opportunities along newly arising surfaces (Antonelli et al. 2018a).

The uplift of the tropical Andes, for example, was instrumental in the development of biodiversity and humidity entrapment in the Neotropics, including the Amazon basin. It created both dispersal barriers and opportunities for colonization and diversification through novel high-elevation environments and greater topographic complexity, as well as for dispersal along newly opened routes. Uplift and other geomorphological processes created diverse mountain morphologies (Elsen and Tingley 2015), as well as complex and unique landscapes of ridges, valleys, peaks, and plateaus (Molnar 2018). With recent methodological advances in thermochronology and paleoaltimetry (e.g. Antonelli et al. 2018a; Perrigo et al. 2019), estimations of the timing and rate of these processes are becoming increasingly precise, robust links can be drawn between spatial biogeographic patterns, and geological scenarios can be tested. Such techniques revealed, for example, that some mountain systems such as the Southern Alps in New Zealand uplifted in the past 15 million years (Myr) whereas others such as the European Alps appeared longer ago.

The interaction between novel topographies, tectonic and erosional processes, regional climates partly dictated by the geographic location of mountains and their orientation in relation to global atmospheric circulation patterns (Antonelli et al. 2018a), and shifts in climate patterns subsequently served to increase environmental heterogeneity and achieve the extraordinary diversity of species and life histories in mountains.

Over the last three or more Myr, successive climatic cycles modified patterns of biodiversity by stimulating geographic-range shifts within mountain regions and between mountains and adjacent lowlands, driving rapid altitudinal migrations upslope during interglacial and downslope during glacial periods, temporarily opening pathways or creating barriers for dispersal to new environments, or dividing and isolating populations.

Accordingly, species richness can be envisioned as the result of multiple episodes of diversification triggered by the consecutive connection and isolation of mountains and species, a hypothesis described in the so-called "flickering connectivity system" framework (Flantua and Hooghiemstra 2018; Flantua et al. 2019). This hypothesis builds on the premise that changes in historical connectivity are important - and possibly as important or even more so than mere isolation - in determining present biodiversity, with historically connected areas characterized by higher species richness (Flantua and Hooghiemstra 2018).

An important fragmentation mechanism associated with climatic cyclicity that played an important role in the diversification of species, such as birds in the Southern Alps of New Zealand (see Flantua and Hooghiemstra 2018) or plants in the Tibeto-Himalayan region (Mosbrugger et al. 2018; see MuellnerRiehl 2019), comes from ice caps on mountaintops and ridges. Yet, while fragmenting habitats, ice also created islands of ice-free habitats, microrefugia from where species such as Saxifraga florulenta in the Maritime Alps could recolonize downhill habitats after episodes of warming (see Patsiou et al. 2014).

Accordingly, the glacial and interglacial periods resulting from climatic fluctuations also played an important role in triggering the evolutionary mechanisms driving presentday species diversity (e.g. Theodoridis et al. 2017), including fragmentation, hybridization, speciation, and extinction (Rahbek et al. 2019b), which all varied in time and space among species and mountain ranges, leaving unique "mountain fingerprints" (Flantua and Hooghiemstra 2018).

\section{The future: why and how to learn from the past}

In view of expected changes in present climatic conditions, a better understanding of past species' community dynamics (see Koutsodendris et al. 2019) and of the relationship between environmental transitions and temporal dynamics in morphological and functional traits (Papadopoulou and Knowles 2016; Huang et al. 2019; MuellnerRiehl 2019) can extend the lead-time for adopting sustainable management and adaptation measures. This is particularly important in high elevation and artic regions 

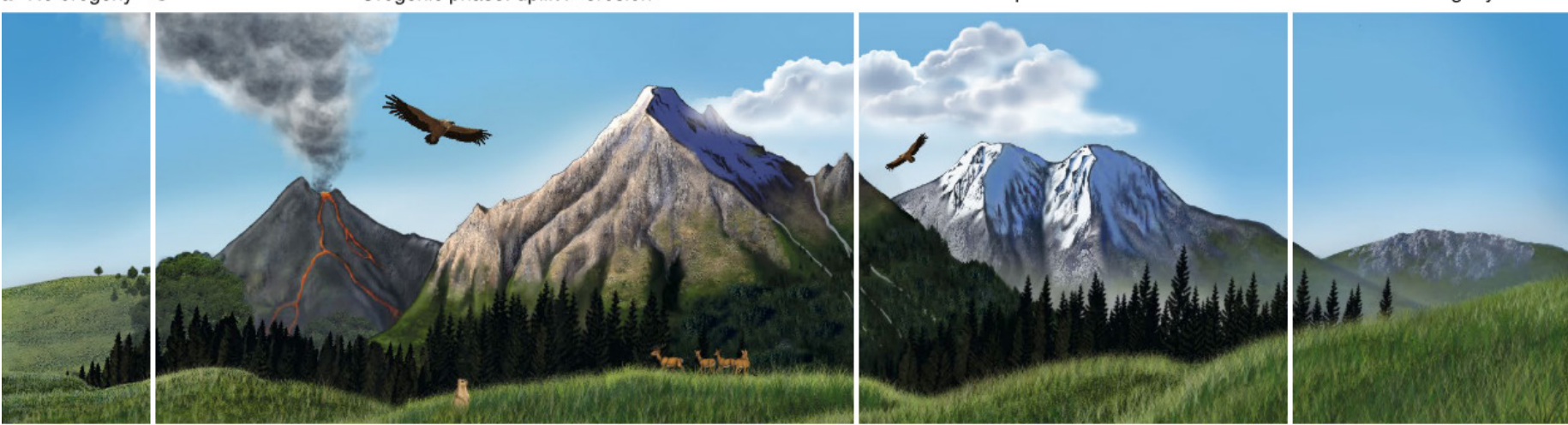

Climatic and geological processes

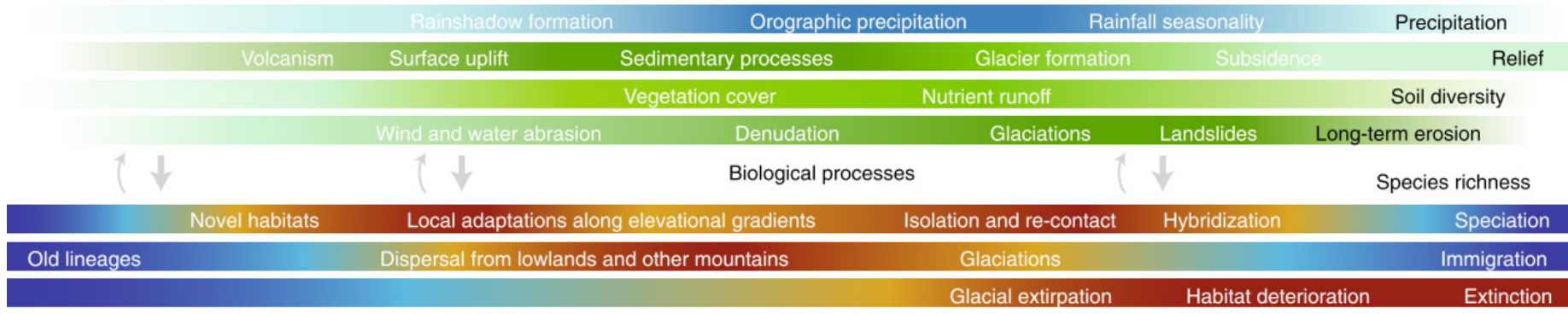

Figure 1: Linking the evolution of mountains and biodiversity. (A-D) Climatic (blue bar) and geological (green bars) variables influence species richness through speciation, immigration, and extinction (lower bars) through different orogenic phases. Darker/warmer and lighter/colder colors in the bars indicate high and low levels, respectively. As the arrows indicate, climatic and geological processes exert the strongest effects on species richness, but some feedbacks exist (such as plants colonizing bare rocks and increasing erosion, and animals affecting soils through burrowing). Figure courtesy of I. Voet, Muséum National d'Histoire Naturelle, Sorbonne Université, Paris; first published in Antonelli et al. (2018a).

exposed to rapid warming (Pepin et al. 2015) and likely to experience particularly severe biodiversity losses (Dullinger et al. 2012) Episodes in Earth's history characterized by temperatures and atmospheric carbon dioxide concentrations comparable to those expected in the near future are therefore particularly informative.

Episodes that can serve as an analogue for a future anthropogenic world are the Pliocene (Burke et al. 2018) and the early Eocene (Hollis et al. 2019), when global temperatures were some degrees warmer than today, atmospheric carbon dioxide concentration was slightly higher, and major shifts in plant communities occurred. Examples of such shifts include the strong expansion of Artemisia at the expense of Chenopodiaceae and other drought-tolerant taxa in the Chinese Loess Plateau (Koutsodendris et al. 2019).

Unraveling the biogeographic history of mountain species, determining the relative role and importance of geomorphological processes and climate on the evolutionary trajectories of species, and learning from the past to inform the future requires interdisciplinary approaches and novel methodologies. Interdisciplinary approaches are needed that integrate expertise across fields and temporal scales from paleobiology and -geology to contemporary conservation, genomics, and remote sensing (see Antonelli et al. 2018b on transdisciplinary biogeography).

Novel methods, in turn, are needed to accurately measure the timing of mountain formation and disentangle the effects of mountain uplift from environmental and climatic changes (Perrigo et al. 2019). Together, approaches from thermochronology or paleoaltimetry have considerably improved models and temporal estimates of mountain uplift (Perrigo et al. 2019). Fitting increasingly robust models with data ranging from fossil records to genome sequences is an effective approach to address the correlative nature of prevalent analyses and the spacefor-time substitution (Perrigo et al. 2019). Paleo-niche reconstructions and modeling combined with phylogenetics and phylogeography are in turn powerful approaches to reconstruct mountain biome dynamics and improve our understanding of the role of these dynamics in shaping current biodiversity patterns (Flantua and Hooghiemstra 2018).

\section{AFFILIATIONS}

'Global Mountain Biodiversity Assessment (GMBA), Institute of Plant Sciences, University of Bern, Switzerland

2Institute for Biodiversity and Ecosystem Dynamics, University of Amsterdam, The Netherlands

${ }^{3}$ Department of Ecology and Evolution, University of Lausanne, Switzerland

${ }^{4}$ Department of Biological Sciences, University of Bergen, Norway

\section{CONTACT}

Davnah Payne: davnah.payne@ips.unibe.ch

\section{REFERENCES}

Antonelli A et al. (2018a) Nat Geosci 11: 718-725 Antonelli A et al. (2018b) PeerJ 6: e5644

Burke KD et al. (2018) Proc Natl Acad Sci USA 115: 13288-13293

Dullinger S et al. (2012) Nat Clim Chang 2: 619-622

Elsen PR, Tingley MW (2015) Nat Clim Chang 5: 772-777
Flantua SGA, Hooghiemstra H (2018) In: Hoorn C et al. (Eds) Mountains, Climate and Biodiversity. Wiley-Blackwell, 171-186

Flantua SGA et al. (2019) J Biogeogr 46: 1808-1825

Gordon JE (2018) In: Hoorn C et al. (Eds) Mountains, Climate and Biodiversity. Wiley-Blackwell, 137-154

Hollis CJ et al. (2019) Geosci Model Dev 12: 3149-3206 Hoorn C et al. (2018) In: Hoorn C et al. (Eds) Mountains, Climate and Biodiversity. Wiley-Blackwell, 1-14

Huang S et al. (2019) J Biogeogr 46: 1777-1791

IPBES (2018) Archer E et al. (Eds) The IPBES regional assessment report on biodiversity and ecosystem services for Africa. Secretariat of the Intergovernmental Science-Policy Platform on Biodiversity and Ecosystem Services, $492 \mathrm{pp}$

Körner C, Ohsawa M (2005) In: Hassan R et al. (Eds) Millenium Ecosystem Assessment- Ecosystems and human wellbeing: current state and trends. Island Press, 681-716

Körner C et al. (2011) Alp Bot 121: 73-78

Körner C et al. (2017) Alp Bot 127: 1-15

Koutsodendris A et al. (2019) Glob Planet Change 180: 117-125

Molnar P (2018) In: Hoorn C et al. (Eds) Mountains, Climate and Biodiversity. Wiley-Blackwell, 17-36

Mosbrugger V et al. (2018) In: Hoorn C et al. (Eds) Mountains, Climate and Biodiversity. WileyBlackwell, 429-448

Muellner-Riehl AN (2019) Front Plant Sci 10: 195

Myers N et al. (2000) Nature 403: 853-858

Papadopoulou A, Knowles LL (2016) Proc Natl Acad Sci USA 113: 8018-8024

Patsiou TS et al. (2014) Glob Chang Biol 20: 2286-2300

Pepin N et al. (2015) Nat Clim Chang 5: 424-430

Perrigo A et al. (2019) J Biogeogr 47: 315-325

Rahbek C et al. (2019a) Science 365: 1108-1113 Rahbek C et al. (2019b) Science 365: 1114-1119 Theodoridis S et al. (2017) Syst Biol 66: 715-736 